\title{
Adsorption of Malachite Green from Aqueous Solutions onto Rice Husks: Kinetic and Equilibrium Studies
}

\author{
V. M. Muinde ${ }^{1}$, J. M. Onyari ${ }^{1}$, B. Wamalwa ${ }^{1}$, J. Wabomba' ${ }^{1}$ R. M. Nthumbi ${ }^{2}$ \\ ${ }^{1}$ Department of Chemistry, College of Biological \& Physical Sciences, University of Nairobi, Nairobi, Kenya \\ ${ }^{2}$ Department of Chemistry, University of Johannesburg, Johannesburg, South Africa \\ Email: *vmuinde@yahoo.com
}

How to cite this paper: Muinde, V.M., Onyari, J.M., Wamalwa, B., Wabomba, J. and Nthumbi, R.M. (2017) Adsorption of Malachite Green from Aqueous Solutions onto Rice Husks: Kinetic and Equilibrium Studies. Journal of Environmental Protection, 8, 215-230.

https://doi.org/10.4236/jep.2017.83017

Received: December 16, 2016

Accepted: January 6, 2017

Published: March 10, 2017

Copyright $\odot 2017$ by authors and Scientific Research Publishing Inc. This work is licensed under the Creative Commons Attribution International License (CC BY 4.0).

http://creativecommons.org/licenses/by/4.0/

\begin{abstract}
A study was done to evaluate the removal of a cationic dye from simulated waste water onto rice husks (RH). Spectroscopic methods such as FTIR and SEM/EDX were used for adsorbent characterization. Experimental dependency on solution $\mathrm{pH}$, initial dye concentration, agitation speed, adsorbentparticle size, temperature of the solution and contact time was evaluated. The adsorption data was tested using both Langmuir and Freundlich isotherms. The data fitted well into Langmuir isotherm model with a monolayer adsorption capacity of $6.5 \mathrm{mg} / \mathrm{g}$. Further, the separation factor $\left(R_{L}\right)$ value was less than unity indicating a favorable adsorption process. Adsorption kinetics was determined using pseudo-first-order, pseudo-second-order and intra-particle diffusion models. The results showed that the adsorption of malachite green onto rice husks followed pseudo-second-order model with a determination coefficient of 0.986 . This work has revealed that rice husks have a great potential to sequester cationic dyes from aqueous solutions and therefore it can be utilized to clean contaminated effluents.
\end{abstract}

\section{Keywords}

Adsorption, Malachite Green, Rice Husks, Isotherm, Cationic Dye

\section{Introduction}

Over the years dyes have been used for coloring industrial products such as food, textile, paper, plastics, pharmaceuticals, cosmetics and tannery [1]. Currently, there are over 10,000 dyes which are used globally. They are synthetic and aromatic in nature which makes them more stable and difficult to biodegrade [2]. Consequently, these recalcitrant dyes have continued to cause deleterious effects 
on human health and aquatic ecosystems due to partial or poor treatment methods before disposal. Some dyes like malachite green (MG) and methylene blue (MB) are carcinogenic and therefore it is important to remove them from effluents with respect to both environmental and aesthetical reasons [3] [4].

Adsorption is an attractive and useful method for the removal of dyes from contaminated water samples. Scientists have adopted it as an alternative technology for eliminating noxious pollutants from water [5]. The process has advantages such as simple design with low investment in terms of initial cost [6]. Various adsorbents have been investigated for elimination of dyes from water samples. These adsorbents include activated carbon [7], straw [8] [9], lignocellulosic substrate from agricultural factories [10] and bagasse fly ash [11]. Some adsorbents used in water purification have some drawbacks. For instance, activated carbon (AC) requires regeneration for re-use and it is also cost-intensive [12].

Rice husks (RH) is a by-product of rice milling factory and accounts for about $20 \%$ of rice products [13]. Utilization of rice husks as a low-cost adsorbent to eradicate pollutants is attracting attention due to its large quantity in the environment. In this work, efficacy of $\mathrm{RH}$ for removal of cationic dye from water was investigated. Dependency of parameters like contact time, dye concentration, $\mathrm{pH}$ and adsorbent dosage on the removal of MG on rice husks was investigated. The objectives of the study were to evaluate the prospect to use $\mathrm{RH}$ to remove malachite green from contaminated water and to characterize the RH using spectroscopic methods such as FTIR, SEM/EDS and BET surface area.

\section{Materials and Methods}

\subsection{Preparation of the Adsorbent}

The rice husks (RH) was obtained from a milling industry in Kenya. It was cleaned with double distilled deionized water to get rid of any adhering dirt. It was air dried and finally dried in the oven (Memmert UM 400, Germany) at $105^{\circ} \mathrm{C}$ for three days to remove moisture. The RH was then sieved into three different particle sizes $(<300,>300<425$, and $>425 \mu \mathrm{m})$ and kept in airtight containers to be used in the subsequent experiments.

\subsection{Preparation of Adsorbate}

Malachite green $\left(\mathrm{C}_{52} \mathrm{H}_{54} \mathrm{~N}_{4} \mathrm{O}_{12}\right.$; C.I. 42,000; molecular weight $927.01 \mathrm{~g} / \mathrm{mol} ; \lambda_{620}$ $\mathrm{nm}$ ) was purchased from Kobian Chemicals limited, Nairobi, Kenya and used as received. A solution of $1000 \mathrm{ppm}$ was prepared using double distilled deionized water. Serial dilution of the stock solution was done and a calibration curve constructed. High purity grade reagents were used. The chemical structure of malachite green is given in Scheme 1.

\subsection{Characterization of Rice Husks (RH)}

FT-IR studies were carried out on a Perkin Elmer spectrophotometer with a scanning range of $4000-400 \mathrm{~cm}^{-1}$. Pellet technique, which utilizes potassium bromide $(\mathrm{KBr})$ for analysis was adopted. Functional groups in both raw and 


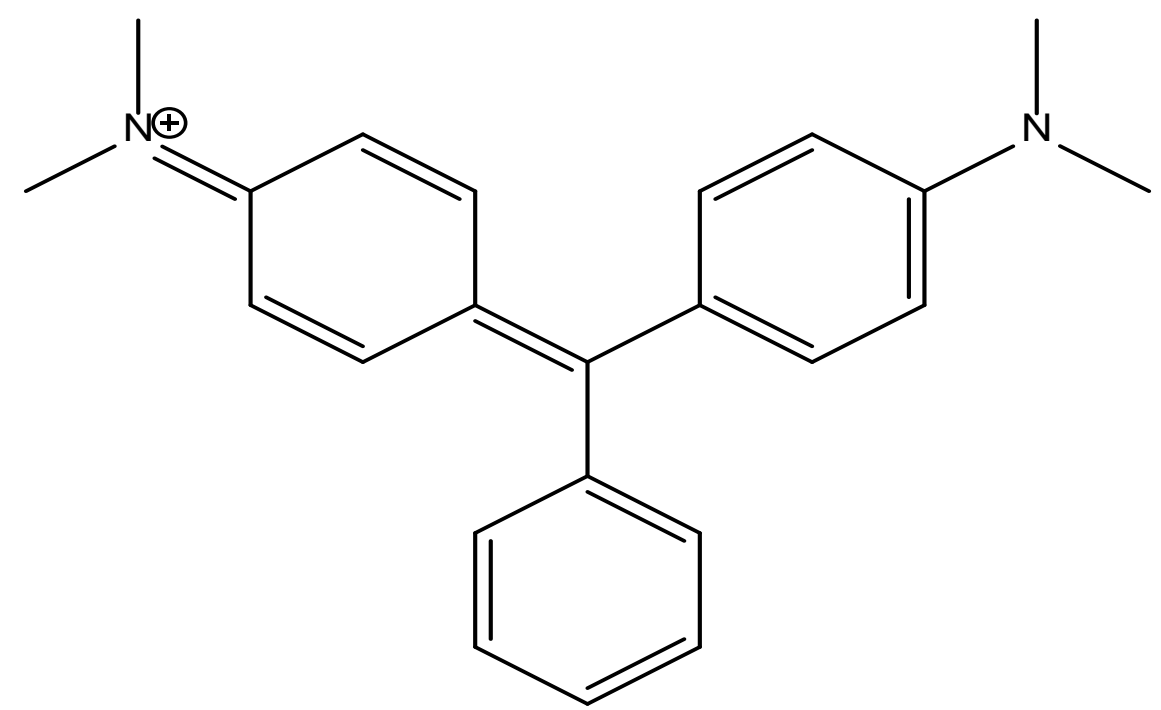

Scheme 1. Chemical structure of malachite green.

reacted $\mathrm{RH}$ were identified from the spectra obtained. The surface morphology of the RH was done using Tescan Vega 3 XMU, (Czech Republic) scanning electron microscope which was coupled with energy dispersive X-ray spectrophotometer for elemental analysis. Surface area and porosity of the RH were determined using nitrogen adsorption method, (Analyzer (BET) micromeritics ASAP 2020, USA).

\subsection{Experimental Design for Batch Adsorption Studies}

\subsubsection{Effect of Contact Time and Initial Dye Concentration}

The above experiments were investigated using $40 \mathrm{~mL}$ of the MG dye in $250 \mathrm{~mL}$ Erlenmeyer flasks. A dosage of $0.1 \mathrm{~g}$ of the rice husks (RH) with particle size of $>$ $300<425 \mu \mathrm{m}$ was used. The flasks were shaken on a Thermolyne orbital shaker at a speed of $200 \mathrm{rpm}$. Varying concentrations of malachite green dye (2.3 - 9.3 $\mathrm{mg} / \mathrm{L}$ ) were prepared for the investigation of influence of initial dye concentration. Analysis of the supernatant solution of MG was measured using a Shimadzu UV-Visible spectrophotometer at a wavelength of $620 \mathrm{~nm}$.

\subsubsection{Effect of Solution $\mathrm{pH}$}

Malachite green (MG) dye solutions with a $\mathrm{pH}$ ranging from 3 to 9 were prepared. The $\mathrm{pH}$ was adjusted to the desired value using either $0.1 \mathrm{M} \mathrm{NaOH}$ or 0.1 $\mathrm{M} \mathrm{HCl}$. $0.1 \mathrm{~g}$ of the adsorbent in $40 \mathrm{~mL}$ of each adjusted MG solution was agitated at $200 \mathrm{rpm}$ at varying time intervals and then the absorbance was measured.

\subsubsection{Effect of Agitation Speed}

Effect of agitation speed was investigated by using a range of shaking speeds (50 - $250 \mathrm{rpm}$ ) for different experiments. $0.1 \mathrm{~g}$ of rice husks in $40 \mathrm{~mL}$ of the dye solution was agitated on an orbital shaker at a $\mathrm{pH}$ of 7 . The initial dye concentration was $9.3 \mathrm{mg} / \mathrm{L}$ whereas the particle size was $>300<425 \mu \mathrm{m}$. 


\subsubsection{Effect of Adsorbent Particle Size}

To evaluate the influence of particle size on the adsorption of malachite green, rice husks (RH) of various meshes $(<300,>300<425$, and $>425 \mu \mathrm{m})$ was utilized. $0.1 \mathrm{~g}$ of $\mathrm{RH}$ in $40 \mathrm{~mL}$ of dye solution was agitated in $250 \mathrm{~mL}$ conical flasks at 200 rpm and $\mathrm{pH}$ of 7 at different time intervals. The dye concentration was kept constant at $9.3 \mathrm{mg} / \mathrm{L}$ for each experiment. A graph of percentage removal (\%) against time in minutes was plotted.

\subsubsection{Effect of Temperature}

Adsorption of malachite green onto rice husks was investigated at 296.15, $303.15,313.15$ and $323.15 \mathrm{~K}$ with initial dye concentration of $9.3 \mathrm{mg} / \mathrm{L}$ and adsorbent dosage of $0.1 \mathrm{~g}$. The solution was shaken at $200 \mathrm{rpm}$ at different time intervals. All experiments were done in triplicates and absorbance measured at a wavelength of $620 \mathrm{~nm}$.

The percentage dye removal (\%) and amount of dye adsorbed on to Rice husks, $q_{e}(\mathrm{mg} / \mathrm{g})$ was computed using Equations (1) and (2), respectively:

$$
\begin{gathered}
\% \text { adsorption }=100\left(C_{o}-C_{e}\right) / C_{o} \\
Q_{e}=\left(C_{o}-C_{e}\right) V / M
\end{gathered}
$$

where $C_{o}$ and $C_{e}$ are initial and equilibrium concentrations $(\mathrm{mg} / \mathrm{L})$ of the dye, $q_{e}$ is amount of dye adsorbed onto the $\mathrm{RH}$ at equilibrium $(\mathrm{mg} / \mathrm{g}), V$ is the volume of the dye used (L) and $M$ is the mass of the adsorbent (g).

\section{Results and Discussion}

\subsection{Characterization of Rice Husks}

\subsubsection{FTIR Analysis}

FT-IR studies for rice husks were carried out using potassium bromide $(\mathrm{KBr})$ pellet technique (Figure 1) with scanning range of $4000-400 \mathrm{~cm}^{-1}$. The broad peak at $3317.41-3900.02 \mathrm{~cm}^{-1}$ stretch indicates presence of $-\mathrm{OH}$ and $-\mathrm{NH}$ groups. The peaks observed at 2913.68 and $1364.37 \mathrm{~cm}^{-1}$ were due to stretching and bending vibration of $\mathrm{C}-\mathrm{H}$ bond in methyl groups respectively (Kushwaha et al. 2014). The peak at $2520.51 \mathrm{~cm}^{-1}$ is characteristic of $-\mathrm{OH}$ from carboxylic acids whereas the stretching around $2014.69-2162.07 \mathrm{~cm}^{-1}$ is due to $-C \equiv C$ from alkynes. The peaks between $1629.45-1732.02 \mathrm{~cm}^{-1}$ are characteristic of carbonyl group.

The presence of $-\mathrm{OH}$ group alongside carbonyl group indicates presence of carboxylic groups in the rice husks. The peak at $1459.11-1508.07 \mathrm{~cm}^{-1}$ is characteristic of aromatic groups whereas the strong peak at $1031.69-1046.79 \mathrm{~cm}^{-1}$ is due to $\mathrm{C}-\mathrm{O}$ bending. The $-\mathrm{OH},-\mathrm{NH}$, carbonyl and carboxyl groups are vital sorption sites [14]. Some peaks shifted after adsorption (3317.41 to 3341.91, 3730.52 to $3788.79,3900.02$ to $3911.20,2520.51$ to 2580.85 and 1629.45 to 1635.73) whereas other peaks disappeared after adsorption (3548.75 and 3511.30). This was a clear indication that adsorption of MG onto rice husks (RH) had taken place and new bonds were formed between MG and RH. 


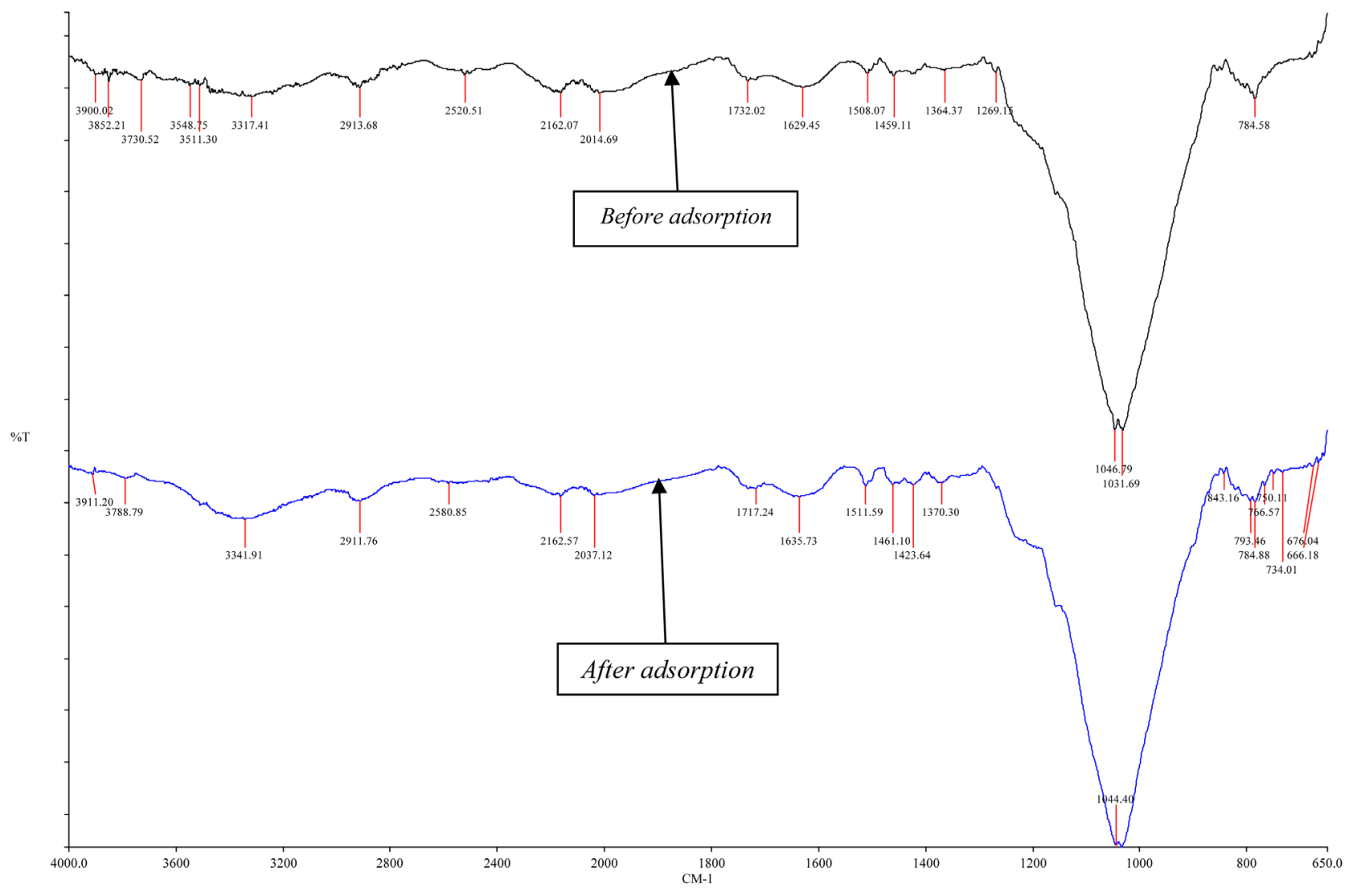

Figure 1. FTIR spectrum before and after adsorption of malachite green.

\subsubsection{SEM/EDX Analysis}

The surface morphology of rice husks was done using scanning electron microscope (SEM) at $150 \times$ magnification (Figure $2 \&$ Figure 3). Figure 2 is a micrograph of rice husks $(\mathrm{RH})$ before adsorption process. It was found that the adsorbent has an irregular porous surface which may be responsible for malachite green adsorption. Figure 3 represents the reacted rice husks with malachite green after adsorption. It is evident that after removal of the dye, the surface of the $\mathrm{RH}$ was smooth implying that the unfilled adsorption sites of the adsorbent were covered by the dye and therefore adsorption had taken place. Elemental analysis of the rice husks (Table 1) indicated substantial amounts of oxygen and silicon ( $42.8 \%$ and $51.82 \%$ respectively). These elements are essential in formation of bonds during adsorption process.

\subsubsection{BET Surface Area and Porosity}

The BET (Brunauer, Emmett and Teller) single point $\left(\mathrm{P} / \mathrm{P}_{\mathrm{o}}\right)$ analysis for the specific surface area was $9.8 \mathrm{~m}^{2} / \mathrm{g}$ whereas the pore volume was $0.068671 \mathrm{~cm}^{3} / \mathrm{g}$. Pore size distribution was $280.3962 \AA$. These parameters affect the extent in which adsorption process takes place.

\subsection{Batch Experiments}

\subsubsection{Effect of Contact Time}

The effect of contact time was evaluated with dye concentration of $9.3 \mathrm{mg} / \mathrm{L}$, 


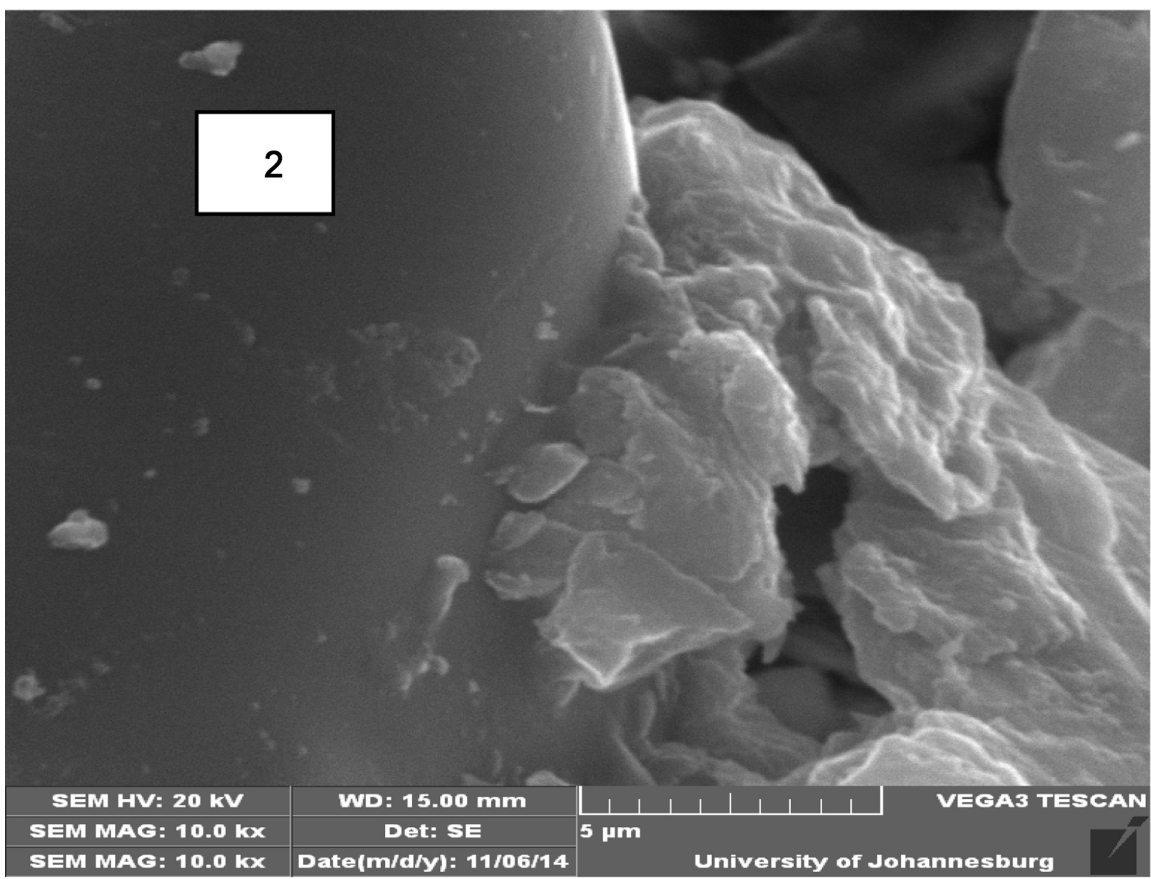

Figure 2. SEM micrograph of raw rice husks.

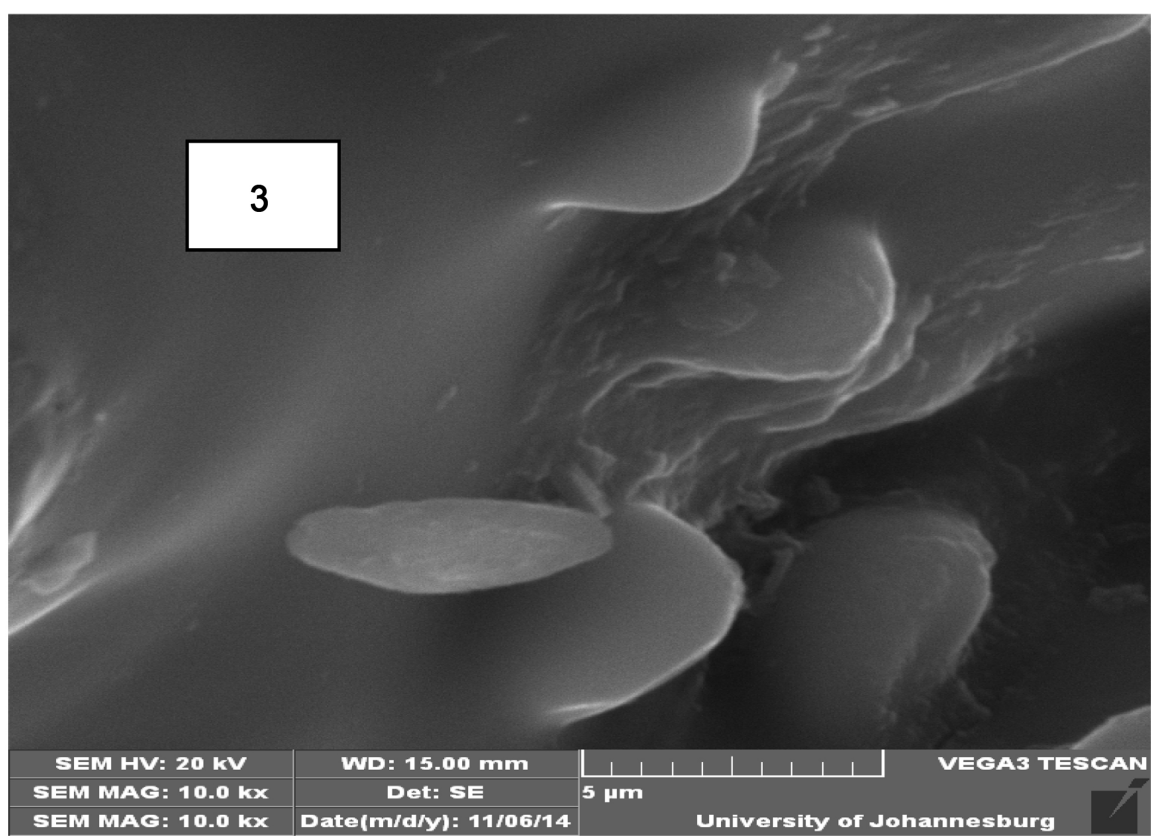

Figure 3. SEM micrograph of reacted rice husks.

adsorbent dosage of $0.1 \mathrm{~g}$, a solution volume of $40 \mathrm{~mL}$ and agitation speed of 200 $\mathrm{rpm}$. The results revealed that the uptake of the dye was rapid at the initial stages of adsorption reaction (30 minutes) and thereafter the adsorption was slow as it approached equilibrium (Figure 4). The above trend of adsorption is ascribed to substantial amount of vacant surface sites accessible for adsorption at the initial stage. However, as the reaction approached equilibrium all the sites were already occupied by the dye hence the adsorption was slow. 


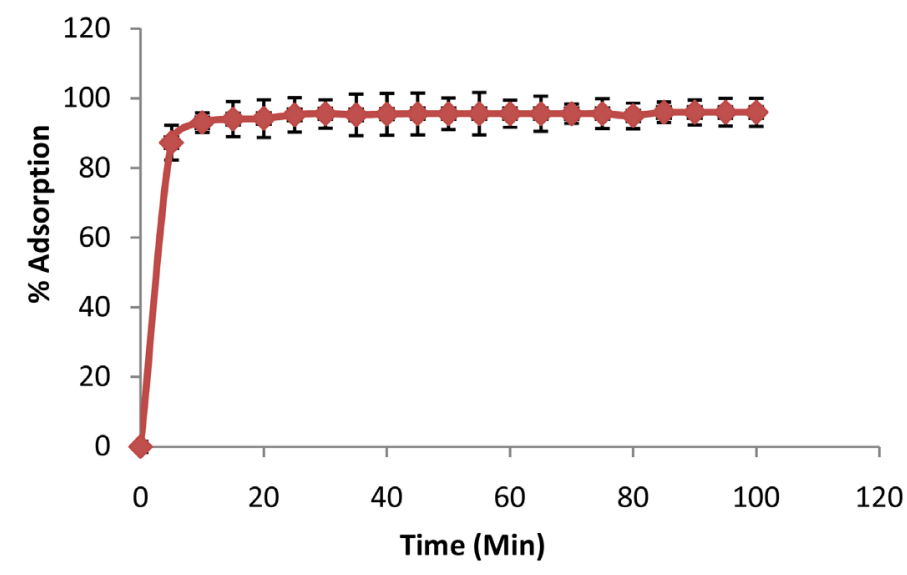

Figure 4. Effect of contact time on malachite green removal by $\mathrm{RH}$.

Table 1. Elemental analysis of rice husks.

\begin{tabular}{ccc}
\hline Element & Weight\% & Atomic\% \\
\hline $\mathrm{O}$ & 42.80 & 57.42 \\
$\mathrm{Mg}$ & 0.22 & 0.19 \\
$\mathrm{Al}$ & 0.59 & 0.47 \\
$\mathrm{Si}$ & 51.82 & 39.61 \\
$\mathrm{P}$ & 0.44 & 0.31 \\
$\mathrm{~S}$ & 0.31 & 0.20 \\
$\mathrm{Ca}$ & 2.08 & 1.12 \\
$\mathrm{Mn}$ & 0.45 & 0.18 \\
$\mathrm{Fe}$ & 1.28 & 0.49 \\
Totals & 100.00 & \\
\hline
\end{tabular}

The curve in Figure 4 indicates probable monolayer coverage of dye on the surface of rice husks. Rajesh et al. [15] recently reported similar results for removal of malachite green on Hydrilla Verticilla biomass. The same trend was also reported by Ahmad and Kumar [16] for the adsorption of malachite green onto treated ginger waste.

\subsubsection{Effect of Initial Dye Concentration}

The influence of initial concentration of malachite green (MG) onto rice husks was investigated with dye concentrations ranging from 2.3 to $9.3 \mathrm{mg} / \mathrm{L}$ and adsorbent dosage of $0.1 \mathrm{~g}$. The percentage (\%) removal decreased with increase of initial dye concentration of MG (Figure 5). The \% decrease in adsorption is ascribed to saturation of the active binding sites of the rice husks at higher concentrations of malachite green.

\subsubsection{Effect of $\mathrm{pH}$}

The $\mathrm{pH}$ of the solution affects the surface charge of the adsorbent and degree of ionization of the dye [17]. In the present study, the $\mathrm{pH}$ values were varied from 3 - 9 (Figure 6) while the other parameters were kept constant. $0.1 \mathrm{M} \mathrm{HCl}$ and $0.1 \mathrm{M} \mathrm{NaOH}$ solutions were used to correct the $\mathrm{pH}$ to the desired value. The percentage (\%) adsorption of the dye increased with increase in $\mathrm{pH}$ up to an 


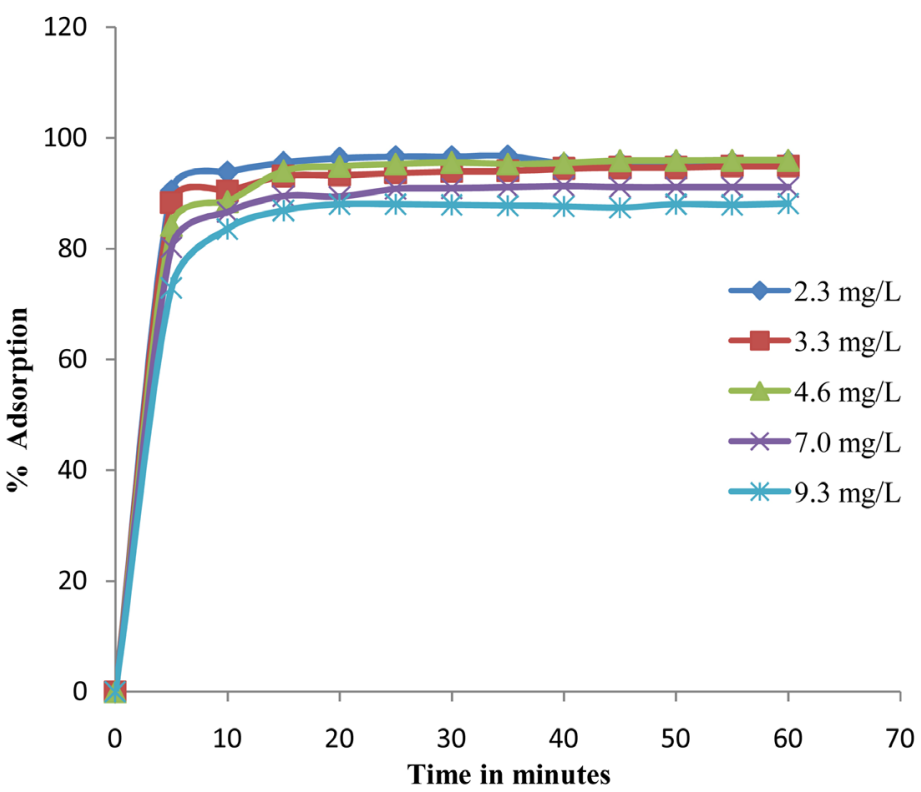

Figure 5. Effect of initial dye concentration on adsorption of MG onto rice husks.

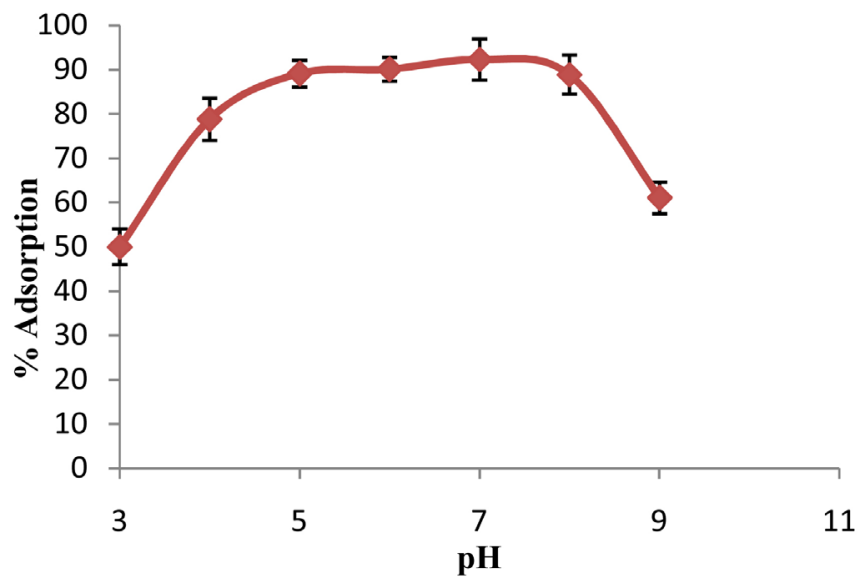

Figure 6. Effect of $\mathrm{pH}$ on adsorption of malachite green onto rice husks.

optimal value of $\mathrm{pH} 7$.

For $\mathrm{pH}$ values greater than 7 , the $\%$ adsorption of the dye decreased hence the optimal $\mathrm{pH}$ of 7 was selected for subsequent experiments. The low adsorption of malachite green (MG) onto rice husks at $\mathrm{pH} 3-6$ could be attributed to $\mathrm{H}^{+}$ions in excess that compete with the dye cations for the adsorption sites [18].

In the $\mathrm{pH}$ range of 8 - 9 the adsorption decreases probably due to formation of soluble hydroxyl complexes.

\subsubsection{Effect of Agitation Speed}

The study was conducted by varying the speed from 50 to $250 \mathrm{rpm}$ on a Thermolyne orbital shaker. Adsorbent dosage was kept constant at $0.1 \mathrm{~g}$, particle size used was $>300<425 \mu \mathrm{m}, \mathrm{pH}$ of 7 and the volume of the dye solution was $40 \mathrm{~mL}$. The maximum removal (93.4\%) of malachite green onto rice husks was achieved 
at $200 \mathrm{rpm}$ and then the adsorption decreased when the agitation speed was increased to $250 \mathrm{rpm}$ (Figure 7). Increasing the agitation speed decreases the boundary of the transfer of dye molecules from the bulk solution to adsorbent surface.

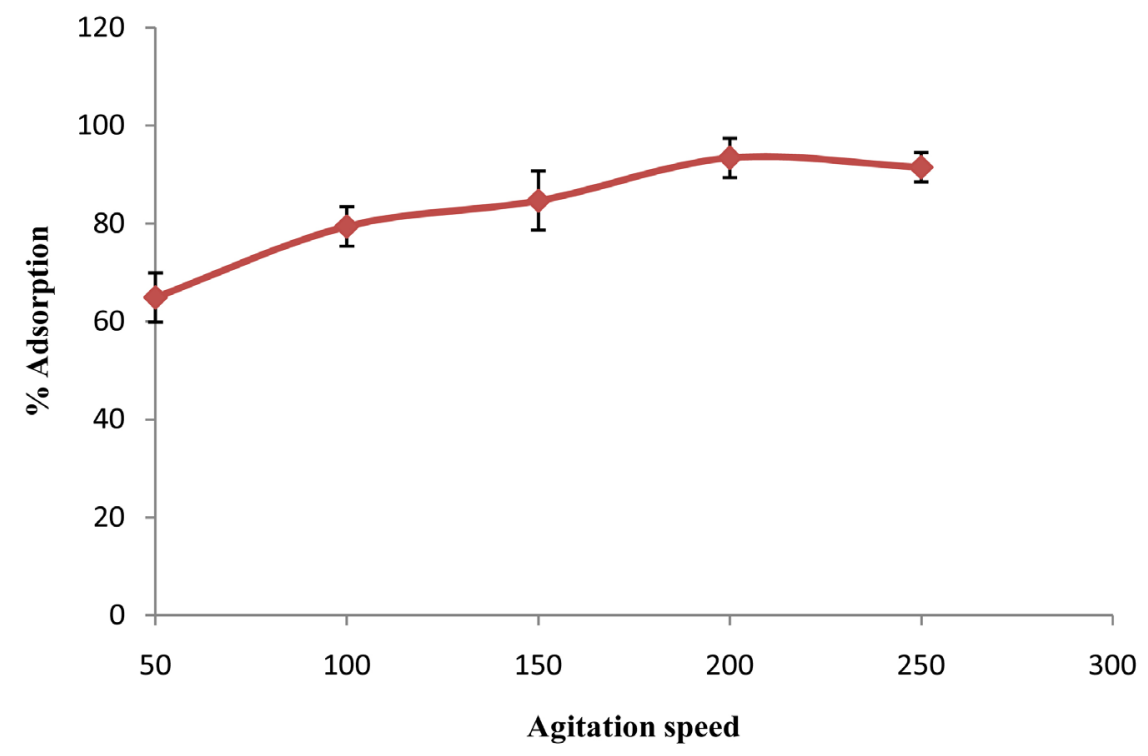

Figure 7. Effect of agitation speed on adsorption of MG onto rice husks.

\subsubsection{Effect of Adsorbent Particle Size on Dye Removal}

The influence of adsorbent particle size on adsorption of malachite green (MG) was tested using three different meshes $(<300,>300<425$, and $>425 \mu \mathrm{m})$. The adsorbent dosage was $0.1 \mathrm{~g}$; volume of the dye solution was $40 \mathrm{~mL}, \mathrm{pH}$ of 7 and shaking speed of $200 \mathrm{rpm}$. The percentage adsorption of MG decreased from 98 to $95 \%$ on increasing the particle size from $>300$ to $>425 \mu \mathrm{m}$ (Figure 8 ). The higher adsorption of MG onto smaller particle size of the adsorbent was attributed to increased accessibility of binding sites due to increased surface area for bulk adsorption of the dye.

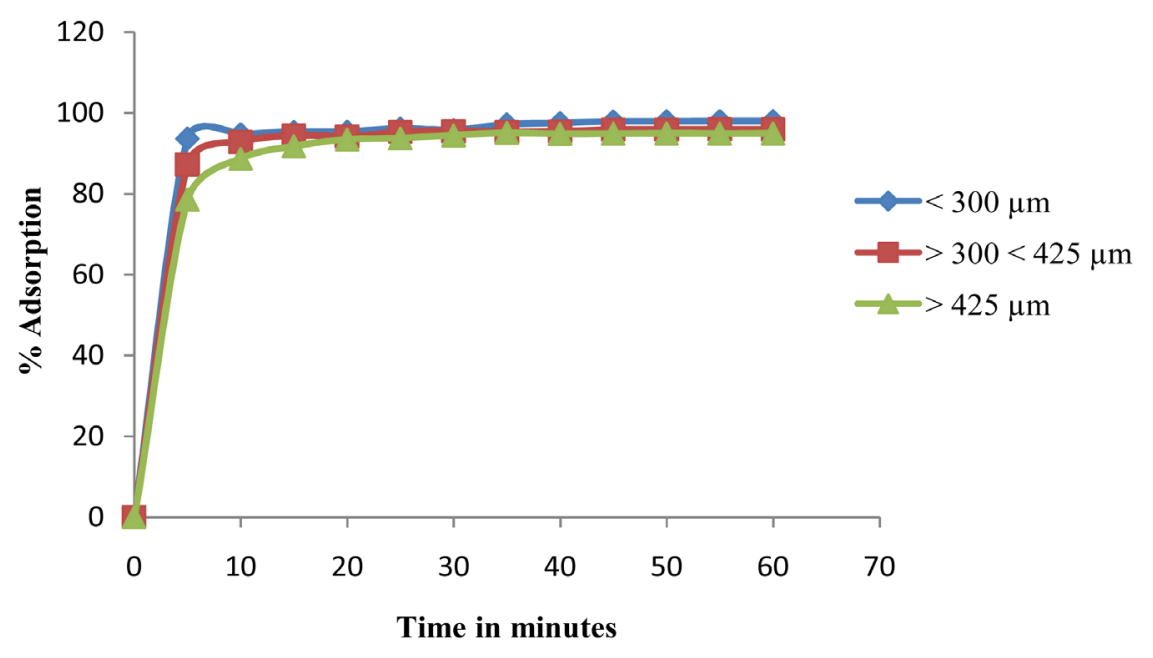

Figure 8. Effect of particle size of RH on malachite green removal. 


\subsubsection{Effect of Temperature on Dye Adsorption}

Experiments were carried out at a temperature range of 296.15 to $323.15 \mathrm{~K}$. The percentage adsorption of malachite green (MG) decreased (97.3\% to $79.0 \%$ ) with increasing temperature implying that the process was exothermic, Figure 9. This could be ascribed to weakening of adsorption forces between the active sites of the adsorbent and adsorbate. Similar results were reported recently in the removal of malachite green using sugarcane baggasse [19].

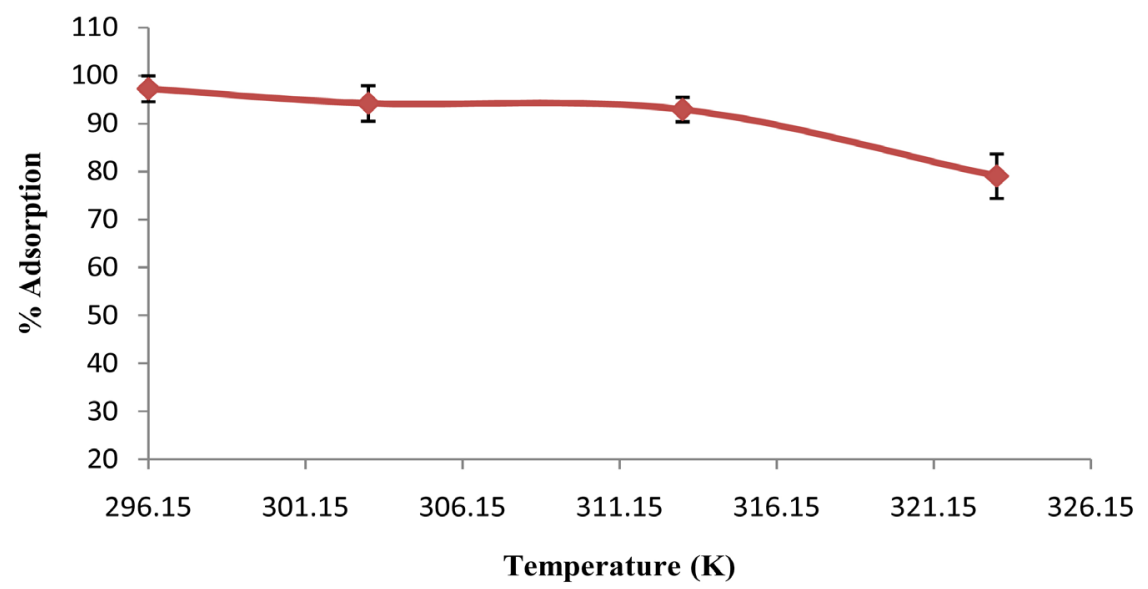

Figure 9. Effect of temperature on adsorption of malachite green dye.

\section{Equilibrium Isotherms}

\subsection{Langmuir Adsorption Isotherm}

The Langmuir equation is commonly expressed as follows [20]:

$$
C_{e} / Q_{e}=1 / K_{L} Q_{m}+C_{e} / Q_{m}
$$

where $Q_{m}$ is monolayer adsorption capacity $(\mathrm{mg} / \mathrm{g}), K_{L}$ is Langmuir isotherm constant. The values of $Q_{m}$ and $K_{L}$ can be calculated by plotting $C_{e} / Q_{e}$ against $C_{e}$ (Figure 10). The essential characteristics of a Langmuir isotherm model can be expressed in terms of dimensionless constant separation factor, $R_{L}[17]$ which is defined by

$$
R_{L}=1 /\left(1+K_{L} C_{o}\right)
$$

The value of $R_{L}$ indicate the type of bio sorption isotherm to be either unfavorable $\left(R_{L}>1\right)$, linear $\left(R_{L}=1\right)$, favorable $\left(0<R_{L}<1\right)$ or irreversible $\left(R_{L}=0\right)$.

The Langmuir isotherm model gave a good fit to the equilibrium adsorption data, with $r^{2}$ of 0.972 compared to Freundlich isotherm which gave determination coefficient of 0.93 . It gave adsorption capacity of $6.5 \mathrm{mg} / \mathrm{g}$ which was slightly higher than $1.484 \mathrm{mg} / \mathrm{g}$ value which was reported recently by Chanzu and coworkers although their $r^{2}$ was 0.704; a value which is lower than what is reported in this study, [17]. This suggested that the removal of malachite (MG) dye followed monolayer coverage onto homogeneous rice husks surface and therefore interaction between dye molecules was neglible [21]. In the present work, the $R_{L}$ value was found to be 0.61 indicating favorable adsorption (Table 2) whereas the $K_{L}$ value was $0.28 \mathrm{~L} \cdot \mathrm{mg}^{-1}$. 


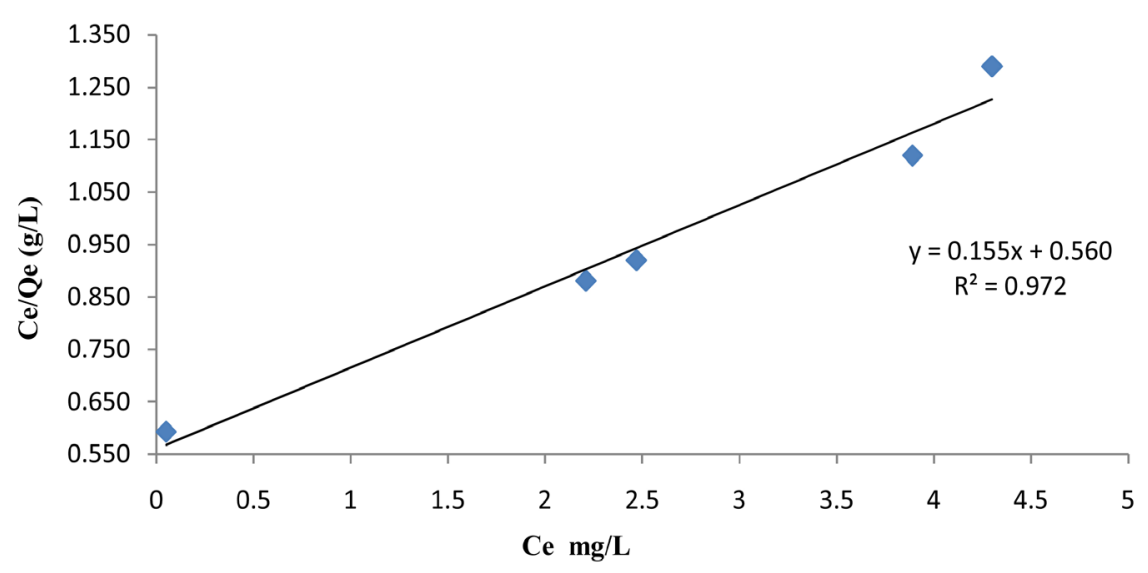

Figure 10. Langmuir adsorption isotherm for adsorption of MG onto rice husks.

\subsection{Freundlich Adsorption Isotherm}

The Freundlich equation was applied for the analysis of the initial dye concentration data obtained from equilibrium studies. The equation assumes a heterogeneous adsorption surface and active sites with different energy. The equation is expressed as follows [4]:

$$
q_{e}=K_{f} C_{e}^{1 / n}
$$

The linear form of Equation (5) is given in the following equation

$$
\ln q_{e}=\ln K_{f}+1 / n \ln C_{e}
$$

where $K_{f}$ and $\mathrm{n}$ are adsorption capacity and intensity respectively and their values can be obtained from intercept and the slope of the graph of $\ln q_{e}$ against $\ln C_{e}$ (Figure 11). Their corresponding values were 0.43 and 27 respectively (Table 2). The results from Freundlich isotherm model gave a lower adsorption capacity $\left(0.43 \mathrm{mg} \cdot \mathrm{g}^{-1}\right)$ of malachite green onto rice husks (RH) compared to that of Langmuir model of $6.5 \mathrm{mg} / \mathrm{g}$. Further, the results demonstrated a better fitting of Langmuir isotherm model than Freundlich model.

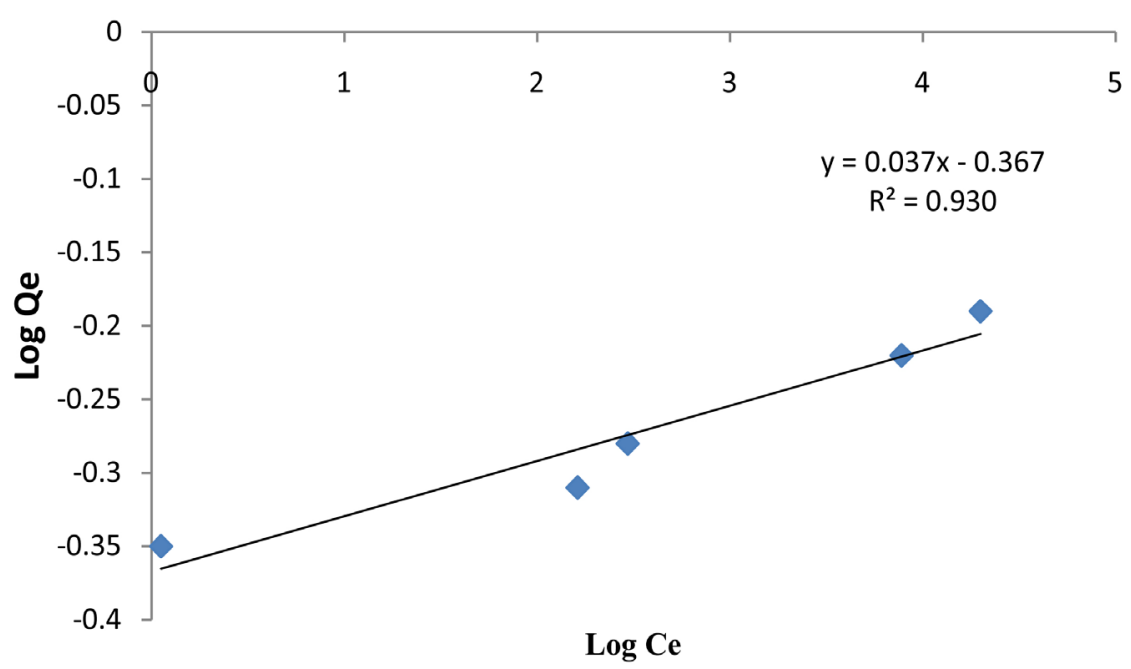

Figure 11. Freundlich adsorption isotherm for removal of MG onto rice husks. 
Table 2. Langmuir and Freundlich isotherm parameters for adsorption of MG onto rice husks.

\begin{tabular}{ccccccc}
\hline \multicolumn{3}{c}{ Langmuir isotherm model constants } & \multicolumn{3}{c}{ Freundlich isotherm model constants } \\
\hline$Q_{m}\left(\mathrm{mg} \cdot \mathrm{g}^{-1}\right)$ & $K_{L}\left(\mathrm{~L} \cdot \mathrm{mg}^{-1}\right)$ & $R_{L}$ & $R^{2}$ & $K_{F}\left(\mathrm{mg} \cdot \mathrm{g}^{-1}\right)$ & $n$ & $R^{2}$ \\
6.5 & 0.28 & 0.61 & 0.972 & 0.43 & 27 & 0.93 \\
\hline
\end{tabular}

\section{Kinetic Studies}

\subsection{Pseudo-First-Order Kinetics on Malachite Green Adsorption}

The kinetic data was fitted into Lagergren pseudo-first-order rate equation which is expressed as [22] [23]:

$$
\log \left(q_{e}-q_{t}\right)=\log q_{e}-k_{1} t / 2.303
$$

where $q_{e}$ and $q_{t}$ are the adsorption capacities at equilibrium and time $\mathrm{t}$ whereas $k_{1}\left(\mathrm{~min}^{-1}\right)$ is the rate constant for the adsorption process. The values of $q_{e}$ and $k_{1}$ are given in Table 3. Adsorption of malachite green (MG) onto rice husks biomass did not follow pseudo-first-order kinetics model since there was no agreement between the experimental $\left(\operatorname{Exp} q_{e}\right)$ and calculated $\left(q_{e}\right.$, cal $)$ adsorption capacities (Table 3). Furthermore, the coefficient of determination $\left(I^{2}\right)$ value was relatively lower (0.78) compared to pseudo-second-order value of 0.986 (Figure 12).

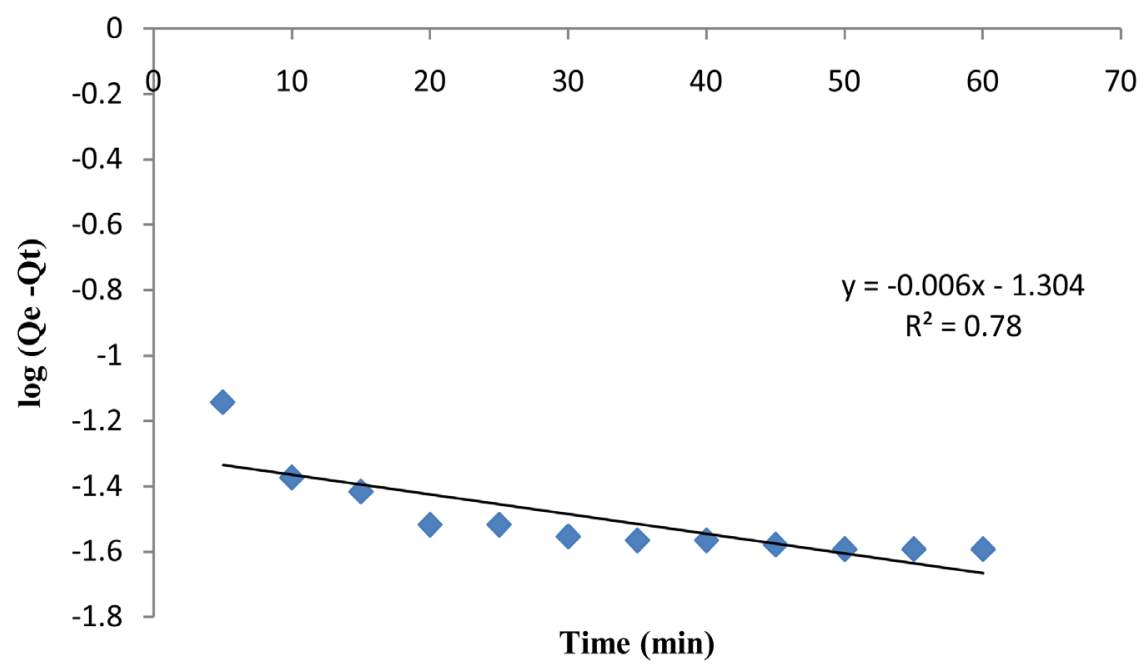

Figure 12. Pseudo-first-order adsorption kinetics of MG onto rice husks.

\subsection{Pseudo-Second-Order Kinetics on Malachite Green Adsorption}

The Lagergren pseudo-second order kinetics equation is expressed in a linear form as shown below [16] [24] [25]:

$$
t / q_{t}=1 / k_{2} q_{e}^{2}+1 / q_{e} t
$$

where the equilibrium adsorption capacity $\left(q_{e}\right)$ and the second order constant $k_{2}$ $\left(\mathrm{g} \cdot \mathrm{mg}^{-1} \cdot \mathrm{min}^{-1}\right)$ can be determined from the slope and intercept of plot of $t / q_{t}$ versus $t$ (Figure 13). The experimental data from this work fitted well into 
pseudo-second-order model with a determination coefficient $\left(R^{2}\right)$ of 0.986$)$. There was good relationship between experimental and calculated value of $q_{e}$ (Table 3) indicating that the adsorption experiment followed pseudo-secondorder than the pseudo-first-order kinetics model. Similar results were reported for removal of methylene blue from aqueous solutions using Eichhornia Crassipes [24]. The second order constant, $k_{2}$ was $4.3 \mathrm{~g} \cdot \mathrm{mg}^{-1} \cdot \mathrm{min}^{-1}$.

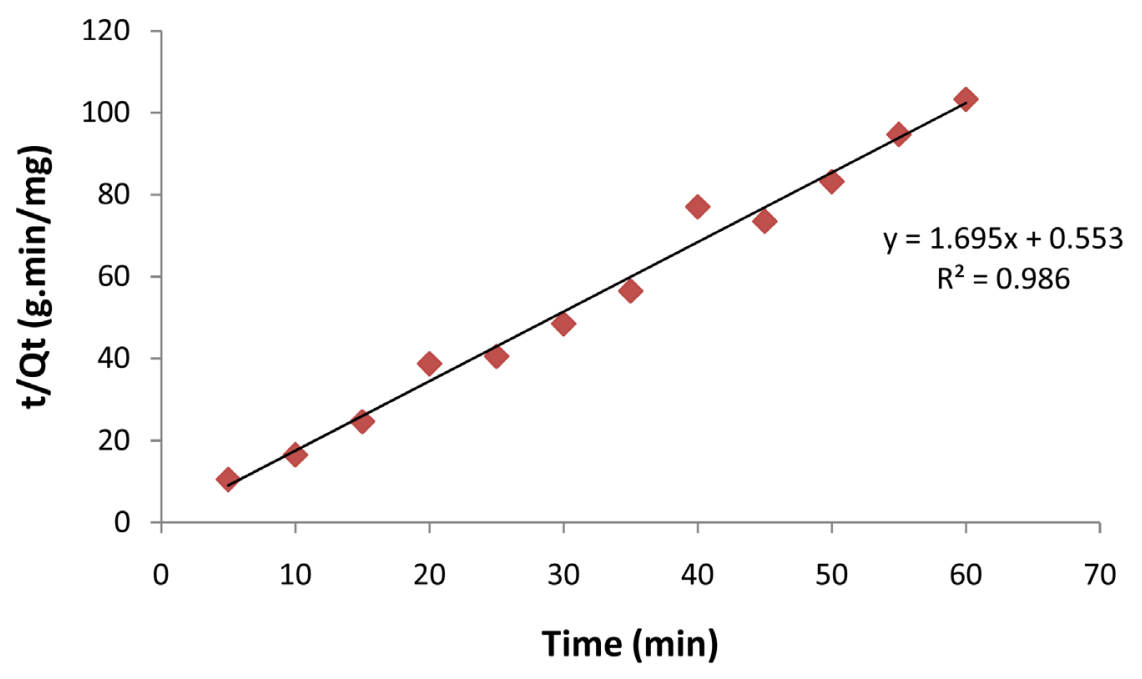

Figure 13. Pseudo-second-order adsorption kinetics of MG onto rice husks.

Table 3. Kinetic parameters for adsorption of MG onto rice husks.

\begin{tabular}{ccccccc}
\hline & \multicolumn{2}{c}{$\begin{array}{c}\text { Pseudo-first } \\
\text { order }\end{array}$} & \multicolumn{3}{c}{ Pseudo-second-order } \\
\hline $\begin{array}{c}\text { Exp } q_{e} \\
\left(\mathrm{mg} \cdot \mathrm{g}^{-1}\right)\end{array}$ & $q_{e}$, cal. $\left(\mathrm{mg} \cdot \mathrm{g}^{-1}\right)$ & $K_{1}\left(\mathrm{~min}^{-1}\right)$ & $R^{2}$ & $q_{e}, \mathrm{cal} .\left(\mathrm{mg} \cdot \mathrm{g}^{-1}\right)$ & $K_{2}\left(\mathrm{~g} \cdot \mathrm{mg}^{-1} \cdot \mathrm{min}^{-1}\right)$ & $R^{2}$ \\
0.622 & 0.05 & 0.014 & 0.78 & 0.625 & 4.3 & 0.986 \\
\hline
\end{tabular}

\subsection{Mechanism of Adsorption of Malachite Green onto Rice Husks}

\section{Weber-Morris Intraparticle Diffusion Model}

The above model was applied to illustrate existence of competitive adsorption processes in the removal of malachite green onto rice husks. The following expression is used to describe the model [4] [26]:

$$
q_{t}=k_{i d} t^{0.5}+c
$$

where $k_{i d}$ is the intra particle diffusion constant $\left(\mathrm{mg} \cdot \mathrm{g}^{-1} \cdot \mathrm{min}^{0.5}\right)$ and $\mathrm{c}$ represents the boundary layer thickness. The values of $k_{i d}$ and c were calculated from the slope and intercept of the graph (Figure 14) of $Q_{t}$ against $\sqrt{t}_{\mathrm{t}}$ in minutes respectively. From the graph, $K_{i d}$ was found to be $0.057 \mathrm{mg} \cdot \mathrm{g}^{-1} \cdot \mathrm{min}^{0.5}$ and c was 0.303 with a determination coefficient $\left(r^{2}\right)$ of 0.966 . Since the line of the graph (Figure 14) did not pass through the origin, it indicates that intra particle diffusion was not the only process controlling the adsorption of malachite green dye onto the rice husks. 


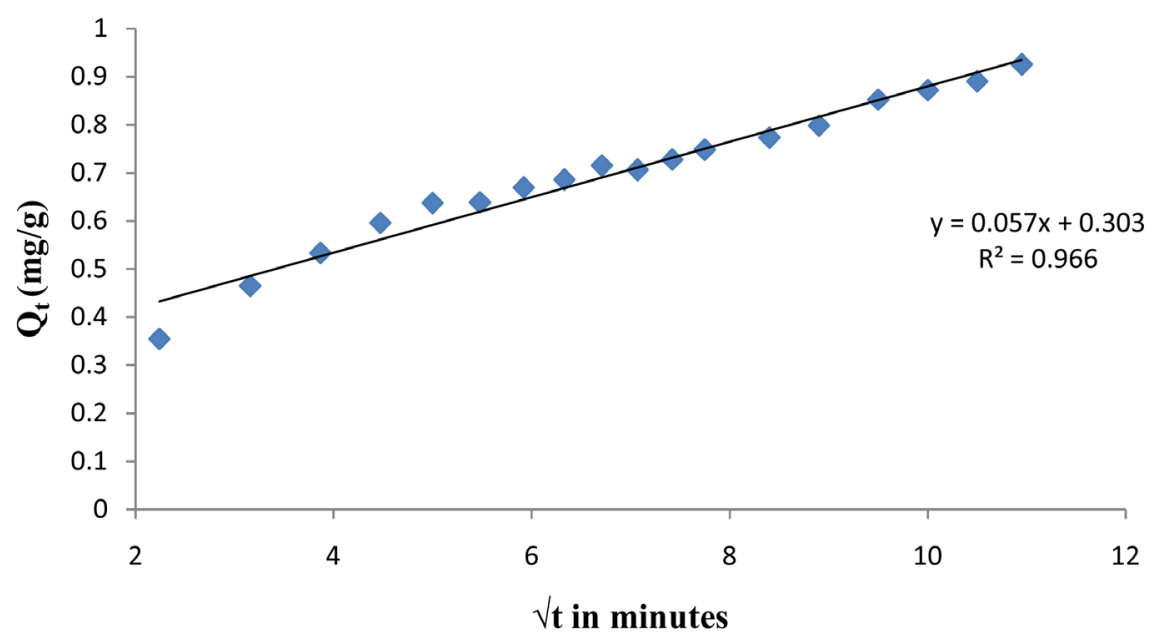

Figure 14. Intraparticle diffusion graph for adsorption malachite green.

\section{Conclusion}

The results obtained from this work indicate that rice husks (RH) can be used as a low-cost adsorbent for sequestering malachite green from aqueous solutions such as waste waters. The characterization studies with scanning electron microscope (SEM) and Fourier transform infra red spectroscopy (FTIR) indicated presence of sufficient pores and functional groups on $\mathrm{RH}$, which can be used in the adsorption process. Further, this study revealed that batch adsorption is influenced by factors such as initial dye concentration, $\mathrm{pH}$ of solution, agitation speed, contact time and temperature. Maximum dye removal of $95.7 \%$ was achieved using initial dye concentration of $2.3 \mathrm{~g} / \mathrm{L}$ and $\mathrm{pH}$ of 7 . The Langmuir adsorption isotherm gave the best fit to the experimental data, suggesting monolayer adsorption on a homogeneous surface. The adsorption kinetics followed the pseudo-second-order model with a determination coefficient $\left(r^{2}\right)$ of 0.986 . The percentage adsorption of malachite green (MG) decreased from $97.3 \%$ to $79.0 \%$ with increasing temperature $(296.15-323.15 \mathrm{~K})$, indicating an exothermic process. The line of intraparticle diffusion graph did not pass through the origin and therefore there were other mechanisms controlling the adsorption of MG onto rice husks.

\section{Acknowledgements}

Deutscher Akademischer Austausch Dienst (DAAD) for the financial support and also University of Nairobi, Department of Chemistry where most of this research was carried out. Finally, we thank Richard M. Nthumbi of University of Johannesburg for his assistance in the characterization of the rice husks adsorbent.

\section{References}

[1] Zhang, H., Tang, Y., Liu, X., Ke, Z., Su, X., Cai, D., Wang, X., Liu, Y., Huang, Q. and Yu, Z. (2011) Improved Adsorptive Capacity of Pine Wood Decayed by Fungi Poria cocos for Removal of Malachite Green from Aqueous Solutions. Desalination, 274, 
97-104. https://doi.org/10.1016/j.desal.2011.01.077

[2] Farajzadeh, M.A. and Fallahi, M.R. (2005) Study of Phenolic Compounds Removal from Aqueous Solution by Polymeric Sorbent. Journal of the Chinese Society, 52, 295-301. https://doi.org/10.1002/jccs.200500045

[3] Kushwala, A.K., Gupta, N. and Chattopadhyaya, M.C. (2010) Adsorption of Malachite Green Dye on Chemically Modified Silica Gel. Journal of Chemical and Pharmaceutical Research, 2, 34-45.

[4] Kushwaha, A.K., Gupta, N. and Chattopadhyaya, M.C. (2014) Removal of Cationic Methylene Blue and Malachite Green from Aqueous Solution by Waste Materials of Daucuscarota. Journal of Saudi Chemical Society, 18, 200-207. https://doi.org/10.1016/j.jscs.2011.06.011

[5] Gupta, V.K., Jain, C.K., Chandra, S. and Agarwal, S. (2002)) Removal of Lindane and Malathion from Waste Water Using Bagasse fly Ash, a Sugar Industry Waste. Water Research, 36, 2483-2490. https://doi.org/10.1016/S0043-1354(01)00474-2

[6] Srivastava, B., Jhelum, V., Basu, D. and Patanjali, P.K. (2009) Adsorbents for Pesticide Uptake from Contaminated Water. A Review. Journal of Scientific and Industrial Research, 68, 839-850.

[7] Sun, D., Zhang, Z., Wang, M. and Wu, Y. (2013) Adsorption of Reactive Dyes on Activated Carbon Developed from Enteromorphaproriera. American Journal of Analytical Chemistry, 4, 17-26. https://doi.org/10.4236/ajac.2013.47A003

[8] Chen, X., Chen, X., Wan, X., Weng, B. and Huang, Q. (2010) Water Hyacinth (Eichhrniacrassipes) Waste as an Adsorbent for Phosphorus Removal from Swine Waste Water. Bioresource Technology, 101, 9025-9030. https://doi.org/10.1016/j.biortech.2010.07.013

[9] Valipour, A., Raman, V.K. and Ghole, V.S. (2011) Phytoremediation of Domestic Waste Water Using Eichhorniacrassipes. Journal of Environmental Science and Engineering, 53, 183-190.

[10] Boudesocque, S., Guillon, E., Aplincourt, M., Martel, F. and Noël, S. (2008) Use of Low-Cost Biosorbent to Remove Pesticides from Waste Water. Journal of Environmental Quality, 37, 631-638. https://doi.org/10.2134/jeq2007.0332

[11] Gupta, V. and Ali, I. (2001) Removal of DDD and DDE from Waste Water Using Bagasse Fly Ash, a Sugar Industry Waste. Water Research, 35, 33-40. https://doi.org/10.1016/S0043-1354(00)00232-3

[12] Chiung, F.C., Ching, Y.C., Kuo, E.H., Shu, C.L. and Wolfgang, H. (2008) Adsorptive Removal of the Pesticide Methomylusing Hyper Cross Linked Polymers. Journal of Hazardous Material, 155, 295-304. https://doi.org/10.1016/j.jhazmat.2007.11.057

[13] Mansaray, K.G. and Ghaly, A.E. (1998) Thermo Gravimetric Analysis of Rice Huskss in an Air Atmosphere. Energy Source, 20, 653-663.

https://doi.org/10.1080/00908319808970084

[14] Poojari, A.C., Maind, S.D. and Bhalerao, S.A. (2015) Effective Removal of Cr (VI) from Aqueous Solutions Using Rind of Orange (Citrus Sinensis) (L.) Osbeck. International Journal of Current Microbiology and Applied Sciences, 4, 653-671.

[15] Rajesh, K.R., Rajasimman, M., Rajamohan, N. and Sivaprakash, B. (2010) Equilibrium and Kinetic Studies on Sorption of Malachite Green Using Hydrilla verticillata biomass. International Journal of Environmental Research, 4, 817-824.

[16] Ahmed, R. and Kumar, R. (2010) Adsorption Studies of Hazardous Malachite Green onto Treated Ginger Waste. Journal of Environmental Management, 91, 1032-1038. https://doi.org/10.1016/j.jenvman.2009.12.016

[17] Chanzu, H.A., Onyari, J.M. and Shiundu, P.M. (2012) Biosorption of Malachite 
Green from Aqueous Solutions onto Polylactide/Spent Brewery Grains Films: Kinetic and Equilibrium Studies. Journal of Polymers and the Environment, 20, 665672. https://doi.org/10.1007/s10924-012-0479-5

[18] Hameed, B.H. and El-Khaiary, M.I. (2008) Malachite Green Adsorption by Rattan Sawdust: Isotherm, Kinetic and Mechanism Modeling. Journal of Hazardous Materials, 159, 574-579. https://doi.org/10.1016/j.jhazmat.2008.02.054

[19] Sharma, N. and Nandi, B.K. (2013) Utilization of Sugarcane Baggase, an Agricultural Waste to Remove Malachite Green Dye from Aqueous Solutions. Journal of Materials and Environmental Science, 4, 1052-1065.

[20] Langmuir, I. (1916) The Constitution and Fundamental Properties of Solids and Liquids. Journal of the American Chemical Society, 38, 2221-2295. https://doi.org/10.1021/ja02268a002

[21] Ofomaja, A.E. and Ho, Y.S. (2008) Effect of Temperatures and pH on Methyl Violet Biosoption by Mansonia Wood Sawdust. Bioresource Technology, 99, 5411-5417. https://doi.org/10.1016/j.biortech.2007.11.018

[22] Labidi, N.S. and Kacemi, N.E. (2016) Adsorption Mechanism of Malachite Green onto Activated Phosphate Rock: A Kinetics and Theoretical Study. Bulletin of Environmental Studies, 1, 69-74.

[23] Khope, R.U. and Gawande, N.J. (2015) Kinetic Models for the Adsorption of Cobalt from Aqueous Phase Using Granular Activated Carbon. Journal of Chemical and Pharmaceutical Research, 7, 551-556.

[24] Wanyonyi, W.C., Onyari, J.M. and Shiundu, P.M. (2013) Adsorption of Methylene Blue Dye from Aqueous Solutions Using Eichhrnia crassipes. Bulletin of Environmental Contamination and Toxicology, 91, 362-366. https://doi.org/10.1007/s00128-013-1053-0

[25] Ho, Y.S. and McKay, G. (1999) Pseudo-Second Order Model for Sorption Processes. Process Biochemistry, 34, 451-465. https://doi.org/10.1016/S0032-9592(98)00112-5

[26] Weber, W.J. and Morris, J.C. (1963) Kinetics of Adsorption on Carbon from Solutions. Journal of the Sanitary Engineering Division, 89, 31-39.

\section{Scientific Research Publishing}

Submit or recommend next manuscript to SCIRP and we will provide best service for you:

Accepting pre-submission inquiries through Email, Facebook, LinkedIn, Twitter, etc. A wide selection of journals (inclusive of 9 subjects, more than 200 journals) Providing 24-hour high-quality service User-friendly online submission system Fair and swift peer-review system Efficient typesetting and proofreading procedure

Display of the result of downloads and visits, as well as the number of cited articles Maximum dissemination of your research work

Submit your manuscript at: http://papersubmission.scirp.org/

Or contact jep@scirp.org 